\title{
Epidemiological profile of systemic sclerosis in the southeast region of Romania
}

\author{
CARMEN BOBEICA $^{1 *}$, ELENA NICULET $^{2}$, MIHAELA CRAESCU $^{2 *}$, CRISTIAN ONISOR $^{2}$, FLORIN BUJOREANU $^{3}$, \\ MIRUNA LUMINITA DRAGANESCU ${ }^{4}$, IOANA ALINA HALIP ${ }^{1}$ and LAURA GHEUCA-SOLOVASTRU ${ }^{5 *}$ \\ ${ }^{1}$ Department of Dermato-Venereology, 'Gr. T. Popa' Doctoral School University of Medicine and Pharmacy, \\ Iași 700115; ${ }^{2}$ Department of Morphological and Functional Sciences, Faculty of Medicine and Pharmacy, \\ 'Dunărea de Jos' University of Galați, Galați 800216; ${ }^{3}$ Department of Clinical Dermato-Venereology, 'Sf. Cuvioasă \\ Parascheva' Infectious Diseases Clinical Hospital, Galați 800179; ${ }^{4}$ Department of Clinical Infectious Diseases, Faculty of \\ Medicine and Pharmacy, 'Dunărea de Jos' University of Galați, Galaţi 800216; ${ }^{5}$ Department of Clinical Dermato-Venereology, \\ 'Gr. T. Popa' University of Medicine and Pharmacy, Faculty of Medicine and Pharmacy, Iași 700115, Romania
}

Received September 18, 2020; Accepted October 20, 2020

DOI: $10.3892 /$ etm.2020.9509

\begin{abstract}
Systemic sclerosis (SSc) is a collagenosis, in which the microvasculature of the skin and internal organs becomes affected, followed by excessive deposition of connective tissue. It has been included in the group of rare diseases, and it seems to have had an increasing incidence over the last two decades. Statistics show, not only an increase in the incidence of SSc, but that of autoimmune diseases as a whole. The present study aimed to outline the epidemiological profile of SSc in the southeast region of Romania and to identify similarities and differences concerning the epidemiology of this disease in other countries. The current observational study was carried out on a group of 22 patients who were diagnosed with SSc and who were hospitalized at a university clinic in Bucharest. Our research revealed a higher prevalence of women suffering from SSc, with higher numbers suffering from the diffuse subset of this disease. In addition, we found that the majority of patients came from urban areas. SSc has an important impact on the quality of life of patients, thus opening the opportunity for studies to be carried out on larger populations of patients in
\end{abstract}

Correspondence to: Assistant Professor Dr E. Niculet, Department of Morphological and Functional Sciences, Faculty of Medicine and Pharmacy, 'Dunărea de Jos' University of Galați, 35 Alexandru Ioan Cuza Street, Galati 800216, Romania

E-mail: helena_badiu@yahoo.com

Associate Professor Dr M.L. Draganescu, Department of Clinical Infectious Diseases, Faculty of Medicine and Pharmacy, 'Dunărea de Jos' University of Galați, 35 Alexandru Ioan Cuza Street, Galati 800216, Romania

E-mail: draganescumiruna@yahoo.com

*Contributed equally

Key words: systemic sclerosis, epidemiological profile, skin fibrosis, collagenosis, autoimmune, microvasculopathy order to identify epidemiological similarities and differences in various countries, as well as finding new experimental models useful for future research.

\section{Introduction}

Systemic sclerosis (SSc), a connective tissue disorder with an insufficiently known etiopathogenesis, is characterized by cutaneous and visceral microvasculopathy followed by excessive fibrosis $(1,2)$. Skin fibrosis is the defining clinical element of this disease and a major clinical criterion according to the 2013 American College of Rheumatology (ACR)/European League Against Rheumatism (EULAR) classification criteria for systemic sclerosis, being present in most patients, with the exception of a small number of cases in which the subset systemic sclerosis sine scleroderma is present (3). Depending on the extension of the lesions, skin damage may occur as limited or diffuse subsets, the latter being most commonly associated with major visceral complications (4). In SSc with limited skin involvement, cutaneous fibrosis is present distally in the hands, feet and face; in SSc with diffuse skin impairment, skin induration is extended centripetally to the trunk (5). SSc has been included in the group of rare diseases, and SSc appears to have had an increasing incidence over the past two decades.

Statistics show, not only an increase in the incidence of SSc, but in autoimmune diseases as a whole. Thus, in Denmark, between 1995 and 2015, there were 2,778 newly diagnosed cases of SSc with an average age of 55 at diagnosis, $76 \%$ being women. Compared to the interval between $1995-$ 2001 and 2002-2008, in which 830 and 887 new cases of SSc were registered, between 2009 and 2015, an increase in 1,061 new cases was observed, showing a constant increase in the incidence of this disease (6). Other studies have revealed a higher incidence of SSc in northern European countries as compared to the southern ones (6-15). Contrary to these observations, a study conducted in Sweden found a much higher incidence of SSc (16). A peak incidence of SSc of 22.8 cases 
per million has been observed in South Australia (17), 19.3 cases per million in the USA (3), and in Taiwan only 10.9 cases per year per million inhabitants was found (18). Choctaw Native Americans have a double prevalence of this disease over other ethnic groups (19), and black women seem to be the most affected ones, with early onset and frequent diffuse SSc form involvement (20). A slight decrease was observed in the prevalence of SSc among women, 73\% in between 2009 and 2015, as compared to the interval between 1995 and 2001 with 79 and $77 \%$, respectively, during 2002 and 2008. However, the sex ratio of women to men remained around 4:1 and the average age at diagnosis has increased in the last decade (21). These results reflect an incidence similar to other statistics. Thus, Della Rossa and co-workers recorded a total ratio of $84 \%$ women in a 2001 study on 290 patients (21), and Steen and co-workers found $83 \%$ women in 1988 out of 397 patients (22). Moreover, Jacobsen and colleagues found $82 \%$ women in 1998 out of 230 patients (23), and Nagy and Czirjac found in their study published in $1997,87 \%$ of patients to be women out of the total $171 \mathrm{SSc}$ patients (24).

\section{Patients and methods}

We conducted an observational study on a group of 22 patients composed mainly of women from urban areas. The mean age of the patients was $55.68 \pm 12.480$ years, with variations between 28 to 76 years. Patients were diagnosed with SSc using the criteria found in the 2013 American College of Rheumatology (ACR)/European League Against Rheumatism (EULAR) (3). In this study, approval was given by the Research Ethics Committee from the Faculty of Medicine in Iasi (24.06.2017), as well as by the Ethics Council of the Clinical Hospital "St. Maria" in Bucharest (5213/04.04.2019). Patients were admitted from February to July 2019 at the Internal Medicine and Rheumatology Wards of the Clinical Hospital "St. Maria" in Bucharest. All data in this study were obtained from the patients' clinical records after they had given their informed consent. All of the procedures in this study were in accordance with the Declaration of Helsinki.

Statistical analysis. The statistical data processing was carried out using SPSS 24.0 (IBM Corp.) using Microsoft Excel. The quantitative data were characterized through descriptive statistics; the qualitative data were characterized through frequency distributions and contingency tables, and the comparisons between samples were made using the Chi-squared test. All P-values were 2-tailed; a P-value of $<0.05$ was considered significant.

\section{Results and discussion}

This study group consisted mainly of women (81.8\%) and from urban areas (63.6\%) (Tables I and II, Figs. 1 and 2).

Patients diagnosed with SSc were divided into two disease subsets, as identified at diagnosis: diffuse SSc, which was the most common subset (68.2\% of cases) and limited SSc, which was found in only $31.8 \%$ of cases, 7 patients, respectively (Table III, Fig. 3).

All male patients were identified with diffuse SSc, together with $61.1 \%$ of female patients (Table IV, Fig. 4); also, in those
Table I. Group structure by sex-frequency distribution.

\begin{tabular}{lcc}
\hline Sex & Absolute frequency & Percentage frequency \\
\hline Female, $\mathrm{n}$ & 18 & 81.8 \\
Male, $\mathrm{n}$ & 4 & 18.2 \\
Total, $\mathrm{n}$ & 22 & 100.0 \\
\hline
\end{tabular}

$\mathrm{n}$, number of patients.

Table II. The structure of the group according to the environment of origin-frequency distribution.

\begin{tabular}{lcc}
\hline Environment & Absolute frequency & Precentage frequency \\
\hline $\mathrm{R}, \mathrm{n}$ & 8 & 36.4 \\
$\mathrm{U}, \mathrm{n}$ & 14 & 63.6 \\
Total, n & 22 & 100.0 \\
\hline
\end{tabular}

n, number of patients. U, urban area; R, rural area.

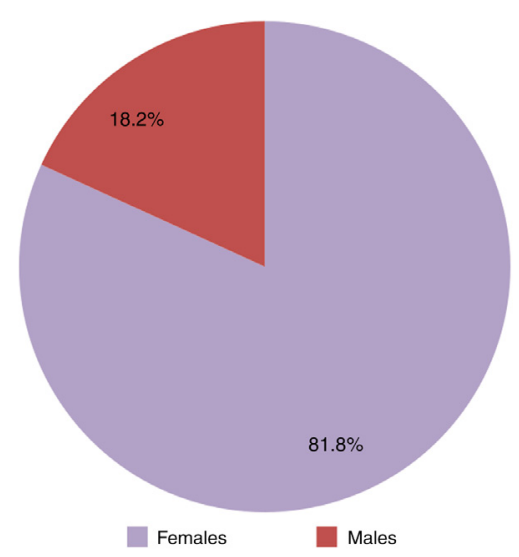

Figure 1. SSc group structure by sex: frequency distribution. SSc, systemic sclerosis.

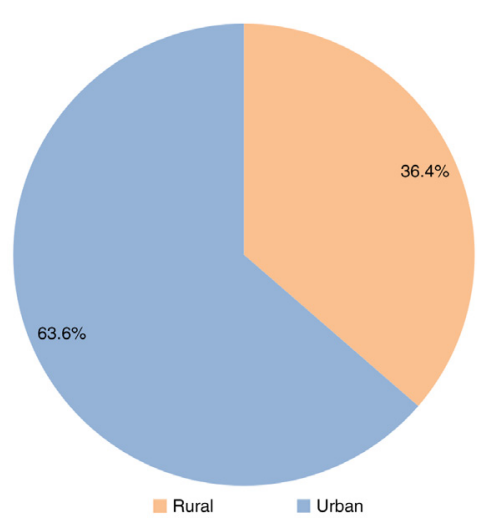

Figure 2. SSc group ratios according to the environment of origin: frequency distribution. SSc, systemic sclerosis.

from the urban area, as well as patients from the rural ones, a clear dominance in the diffuse type of SSc $(75.0 \%$ rural 
Table III. Classification of SSc into disease subsets-frequency distribution.

\begin{tabular}{lcc}
\hline Subset & Absolute frequency & Percentage frequency \\
\hline Diffuse, $\mathrm{n}$ & 15 & 68.2 \\
Limited, $\mathrm{n}$ & 7 & 31.8 \\
Total, $\mathrm{n}$ & 22 & 100.0 \\
\hline
\end{tabular}

$\mathrm{n}$, number of patients. SSc, systemic sclerosis.

Table IV. Classification of SSc into comparative subsets by sex-frequency distribution.

\begin{tabular}{lccc}
\hline \multicolumn{4}{c}{ Subset* sex cross tabulation } \\
\cline { 2 - 3 } & \multicolumn{2}{c}{ Sex } & \\
\cline { 2 - 3 } & Female & Male & Total \\
\hline Subset & & & \\
Diffuse & & & \\
$\quad \mathrm{n}$ & 11 & 4 & 15 \\
$\%$ & 61.1 & 100.0 & 68.2 \\
Limited & & & \\
$\mathrm{n}$ & 7 & 0 & 7 \\
$\%$ & 38.9 & 0.0 & 31.8 \\
Total & & & \\
$\mathrm{n}$ & 18 & 4 & 22 \\
$\%$ & 100.0 & 100.0 & 100.0 \\
\hline
\end{tabular}

SSc, systemic sclerosis. Pearson Chi-square value $=2.281$; $\mathrm{P}=0.131 \mathrm{NS}$, not significant.

patients and 64.3\% urban patients) was found, although without major differences (Table V, Fig. 5). This slight variation was not statistically significant and a correlation between the male patients and the presence of diffuse SSc can be made.

The present study is an observational study aiming to report the epidemiological profile of SSc in the southeast region of Romania. This study took into consideration SSc patients hospitalized in a university hospital in Bucharest. A relatively low prevalence of cases of SSc was suggested due to the small number of patients recruited. SSc is a rare disease, but the incidence has increased slightly in recent years (6).

This study group consisted mainly of women, which is in accordance with the existing literature data stating that over three quarters of SSc patients are women. Several authors, Della Rossa $e t a l$, Steen $e t a l$ and Jacobsen $e t a l$, as well as Nagy and Czirjac, highlighted in their studies from 1997, 1998 and 2001 that only 1/5 SSc patients were male (21-24).

Patients from the two disease subsets (diffuse SSc and limited SSc) were included in this cohort study. Two-thirds of the patients suffered from diffuse SSc. Reports of diffuse and limited cases of SSc are not in line with the studies conducted by Della Rosa et al, Jacobsen et al, Nagy and Czirjac, but
Table V. Classification of SSc into comparative subsets by environment origin-frequency distribution.

\begin{tabular}{lccc}
\hline \multicolumn{4}{c}{ Crosstab } \\
\cline { 1 - 2 } & \multicolumn{2}{c}{ Environment } & \\
\cline { 2 - 3 } & Rural & Urban & Total \\
\hline Subset & & & \\
Diffuse & & & \\
$\mathrm{n}$ & 6 & 9 & 15 \\
$\%$ & 75.0 & 64.3 & 68.2 \\
Limited & & & \\
$\mathrm{n}$ & 2 & 5 & 7 \\
$\%$ & 25.0 & 35.7 & 31.8 \\
Total & & & \\
$\mathrm{n}$ & 8 & 14 & 22 \\
$\%$ & 100.0 & 100.0 & 100.0 \\
\hline
\end{tabular}

SSc, systemic sclerosis. Pearson Chi-square value $=0.269 ; \mathrm{P}=0.60$. NS, not significant.

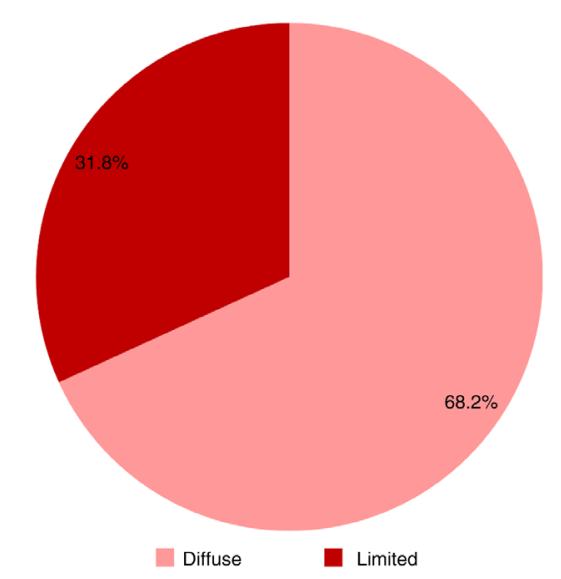

Figure 3. Classification of SSc into disease subtypes: frequency distribution. $\mathrm{SSc}$, systemic sclerosis.

similar results were found in the study conducted by Steen et al, in which diffuse SSc types predominate. These authors revealed a high ratio of limited subsets as follows: Della Rosa and colleagues identified $2 / 3$ of patients with limited SSc in a 2001 multicenter study (Italy, Greece, England, Scotland, Denmark, Poland, Holland, France, Czech Republic) (21), Jacobsen et al observed that $3 / 4$ of patients in Denmark suffered from limited SSc in their 1998 study (23), and Nagy and Czirjac reported more than $3 / 4$ of patients with limited SSc in their 1997 study in Hungary (24). However, Steen and colleagues reported in their 1997 study at the University of Pittsburgh, that the predominant subset was diffuse type, with more than half of the patients suffering from diffuse type (22).

The diffuse subtype of SSc was found in all male patients and two thirds of women in our present study. Although the differences were not statistically significant, a correlation can be made between the male gender of the patients and the 


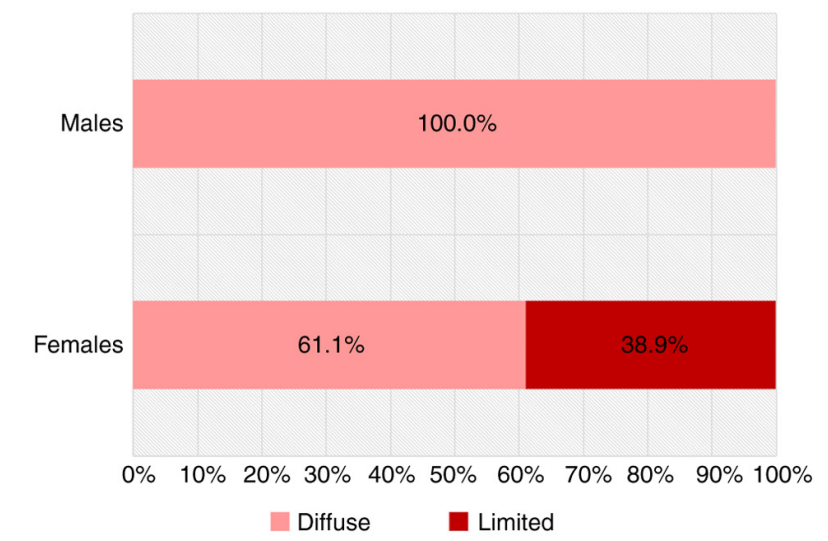

Figure 4. Classification of SSc into comparative subsets by sex: frequency distributions. SSc, systemic sclerosis.

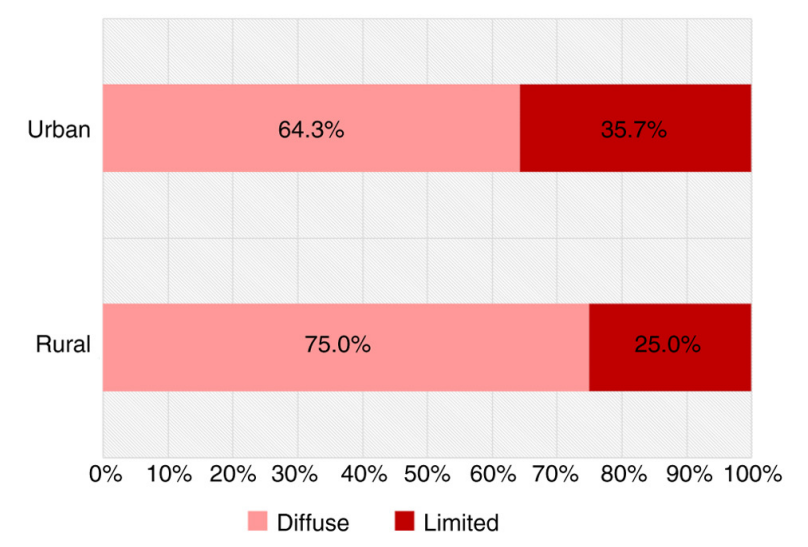

Figure 5. Classification of SSc into comparative subsets by environment of origin: frequency distribution. SSc, systemic sclerosis.

presence of diffuse SSc. Furthermore, in those from the urban areas and those from the rural areas, a clear, but relatively balanced prevalence of diffuse SSc was found.

In conclusion, this study highlights the epidemiological profile of SSc in the southeast region of Romania, with its particularities. Women were found to be more affected by SSc, similar to reports by various studies in other countries, but, as a particularity, the present study revealed the predominance of the diffuse SSc subtype. The results of our study are similar to the ones reported by Steen et al (22), the diffuse subset of SSc being more frequently found; in direct contrast to reports made by other authors. Studies conducted on patient groups from other countries such as Italy, Greece, England, Scotland, Denmark, Poland, Holland, France, Czech Republic, Hungary and Pittsburgh, have shown a higher number of the limited subset of SSc (21-24).

The major impact on the quality of life underlines the opportunity for future studies carried out on larger populations of patients in order to establish epidemiological similarities and differences of SSc in various countries, as well as to identify new experimental models useful in research (25-29). Disease models induced in laboratory animals are useful for identifying etiopathogenic features that could also lead us to the epidemiological profile of groups of patients exposed to different living, geographical or working conditions (27).

\section{Acknowledgements}

Not applicable.

\section{Funding}

No funding was received.

\section{Availability of data and materials}

The analyzed data sets generated during the present study are available from the corresponding author on reasonable request.

\section{Authors' contributions}

$\mathrm{CB}, \mathrm{EN}, \mathrm{MC}, \mathrm{MLD}$ and LGS were involved in the conception of the study and had major contribution in the writing and revising of the manuscript. $\mathrm{CO}, \mathrm{FB}$ and IAH assisted in the acquisition, analysis and interpretation of the data. All authors have read and approved the final manuscript.

\section{Ethics approval and consent to participate}

The present study was approved by the Ethics Review Committees of the Medical University of Iași and of a university clinic of Internal Medicine and Rheumatology in Bucharest and performed in accordance with the Declaration of Helsinki.

\section{Patient consent for publication}

All patients provided informed consent and approved the publication of data.

\section{Competing interests}

The authors declare that they have no competing interests.

\section{References}

1. Barsotti S, Orlandi M, Codullo V, di Battista M, Lepri G, Della Rossa A, et al: One year in review 2019: systemic sclerosis. Clin Exp Rheumatol 37 Suppl 119: 3-14, 2019.

2. Bobeică C, Tatu AL, Crăescu M and Solovăstru L: Dynamics of digital ulcers in systemic sclerosis. Exp Ther Med 20: 61-67, 2020.

3. Masi AT and Medsger TA Jr: Progress in the evolution of systemic sclerosis classification criteria and recommendation for additional comparative specificity studies. J Rheumatol 42: 8-10, 2015.

4. Denton CP: Advances in pathogenesis and treatment of systemic sclerosis. Clin Med (Lond) 15 (Suppl 6): s58-s63, 2015.

5. Cottin V and Brown KK: Interstitial lung disease associated with systemic sclerosis (SSc-ILD). Respir Res 20: 13, 2019.

6. Butt SA, Jeppesen JL, Fuchs C, Mogensen M, Engelhart M, Torp-Pedersen C, Gislason GH, Jacobsen S and Andersson C: Trends in incidence, mortality, and causes of death associated with systemic sclerosis in Denmark between 1995 and 2015: A nationwide cohort study. BMC Rheumatol 2: 36, 2018.

7. Arias-Nuñez MC, Llorca J, Vazquez-Rodriguez TR, GomezAcebo I, Miranda-Filloy JA, Martin J, Gonzalez-Juanatey C and Gonzalez-Gay MA: Systemic sclerosis in northwestern Spain: A 19-year epidemiologic study. Medicine (Baltimore) 87: 272-280, 2008.

8. Hoffmann-Vold AM, Midtvedt $\varnothing$, Molberg $\varnothing$, Garen T and Gran JT: Prevalence of systemic sclerosis in south-east Norway. Rheumatology (Oxford) 51: 1600-1605, 2012. 
9. Kaipiainen-Seppänen $\mathrm{O}$ and Aho $\mathrm{K}$ : Incidence of rare systemic rheumatic and connective tissue diseases in Finland. J Intern Med 240: 81-84, 1996.

10. Geirsson AJ, Steinsson K, Guthmundsson S and Sigurthsson V: Systemic sclerosis in Iceland. A nationwide epidemiological study. Ann Rheum Dis 53: 502-505, 1994.

11. Allcock RJ, Forrest I, Corris PA, Crook PR and Griffiths ID: A study of the prevalence of systemic sclerosis in northeast England. Rheumatology (Oxford) 43: 596-602, 2004

12. Kernéis S, Boëlle PY, Grais RF, Pavillon G, Jougla E, Flahault A, Simonsen L and Hanslik T: Mortality trends in systemic sclerosis in France and USA, 1980-1998: An age-period-cohor analysis. Eur J Epidemiol 25: 55-61, 2010.

13. Alamanos Y, Tsifetaki N, Voulgari PV, Siozos C, Tsamandouraki K, Alexiou GA and Drosos AA: Epidemiology of systemic sclerosis in northwest Greece 1981 to 2002. Semin Arthritis Rheum 34: 714-720, 2005.

14. El Adssi H, Cirstea D, Virion JM, Guillemin F and de Korwin JD: Estimating the prevalence of systemic sclerosis in the Lorraine region, France, by the capture-recapture method. Semin Arthritis Rheum 42: 530-538, 2013.

15. Lo Monaco A, Bruschi M, La Corte R, Volpinari S and Trotta F: Epidemiology of systemic sclerosis in a district of northern Italy. Clin Exp Rheumatol 29 (Suppl 65): S10-S14, 2011.

16. Andréasson K, Saxne T, Bergknut C, Hesselstrand R and Englund M: Prevalence and incidence of systemic sclerosis in southern Sweden: Population-based data with case ascertainment using the 1980 ARA criteria and the proposed ACR-EULAR classification criteria. Ann Rheum Dis 73: 1788-1792, 2014.

17. Roberts-Thomson PJ, Jones M, Hakendorf P, Kencana Dharmapatni AA, Walker JG, MacFarlane JG, Smith MD and Ahern MJ: Scleroderma in South Australia: Epidemiological observations of possible pathogenic significance. Intern Med J 31: 220-229, 2001.

18. Kuo CF, See LC, Yu KH, Chou IJ, Tseng WY, Chang HC, Shen YM and Luo SF: Epidemiology and mortality of systemic sclerosis: A nationwide population study in Taiwan. Scand J Rheumatol 40: 373-378, 2011.

19. Arnett FC, Howard RF, Tan F, Moulds JM, Bias WB, Durban E, Cameron HD, Paxton G, Hodge TJ, Weathers PE, et al: Increased prevalence of systemic sclerosis in a Native American tribe in Oklahoma. Association with an Amerindian HLA haplotype. Arthritis Rheum 39: 1362-1370, 1996.
20. McFarlane IM, Bhamra MS, Kreps A, Iqbal S, Al-Ani F, Saladini-Aponte C, Grant C, Singh S, Awwal K, Koci K, et al: Gastrointestinal manifestations of systemic sclerosis. Rheumatology (Sunnyvale) 8: 235, 2018

21. Della Rossa A, Valentini G, Bombardieri S, Bencivelli W, Silman AJ, D'Angelo S, Cerinic MM, Belch JF, Black CM, Becvar R, et al: European multicentre study to define disease activity criteria for systemic sclerosis. I. Clinical and epidemiological features of 290 patients from 19 centres. Ann Rheum Dis 60: 585-591, 2001

22. Steen VD, Powell DL and Medsger TA Jr: Clinical correlations and prognosis based on serum autoantibodies in patients with systemic sclerosis. Arthritis Rheum 31: 196-203, 1988.

23. Jacobsen S, Halberg P, Ullman S, Van Venrooij WJ, HøierMadsen M, Wiik A and Petersen J: Clinical features and serum antinuclear antibodies in 230 Danish patients with systemic sclerosis. Br J Rheumatol 37: 39-45, 1998.

24. Nagy Z and Czirják L: Predictors of survival in 171 patients with systemic sclerosis (scleroderma). Clin Rheumatol 16 454-460, 1997.

25. Modrigan M, Draganescu M, Condratovici CP, Pavel LL and Condratovici AP: Clinical personality patterns in young adults with HIV nosocomial infection from the region of Southeast Romania. Mater Plast 54: 175-179, 2017.

26. Bobeica C, Vata D, Statescu L, Taranu T, Popescu IA and Grajdeanu AI: The quality of life for a patient with an autoimmune disease. Bull Integr Psychiatry XXV: 27-36, 2019.

27. Bobeica C, Craescu M, Ancuta CI, Coman M and Nechita A: Experimental models for the study of systemic scleroderma. The Annals of "Dunărea de Jos". Univ Galati XVII: 71-84, 2018.

28. Grajdeanu IA, Statescu L, Vata D, Grigorescu C, Popescu IA, Porumb Andrese A, et al: Contribution of imaging techniques in the management of cutaneous pathology. Rev Chim 70: 87-91, 2019.

29. Solovăstru LG, Stîncanu A, De Ascentii A, Capparé G, Mattana P and Vâță D: Randomized, controlled study of innovative spray formulation containing ozonated oil and $\alpha$-bisabolol in the topical treatment of chronic venous leg ulcers. Adv Skin Wound Care 28: 406-409, 2015. 